\title{
ДОДАТОК ДЛЯ ПРОЄКТУВАННЯ ТА АНАЛІЗУ ПЛАНУ БУДІВЛІ ЗГІДНО НОРМ ПОЖЕЖНОЇ БЕЗПЕКИ
}

Анотація. Запропоновано систему для автоматизації перевірки споруд на пожежну безпеку на основі проектної документації. Головним недоліком усіх існуючих програм $\epsilon$ їхня ціна, яка в силу невисокої конкуренції на ринку є досить великою для пересічної людини. Дана розробка є ореn-source програмою, отже кожен охочий зможе скористатися ї функціоналом. На завантаженому або створеному безпосередньо в програмі плані будинку програма виявляє та виділяє проблемні місця та надає пояснення щодо пункту правил та причин його невідповідності. В результаті роботи програми користувач може отримати звіт за результатами аналізу та 2D модель будинку, яку потім можна буде використовувати в інших програмах. Програмний додаток може використовуватись як на етапі проектування будівлі, так і на етапі прийняття в експлуатацію.

Ключові слова: пожежна безпека, системи проєктування, аналіз зображень.

Вступ. Кожного дня в Україні стається десятки, а то й сотні пожеж в житлових та нежитлових приміщеннях. Кожна $з$ них в тій чи іншій мірі завдає шкоди самій будівлі, несе матеріальні збитки, а також створює загрозу людському життю. Часто наслідки пожежі посилюються через недотриманням норм пожежної безпеки, яких можна було б уникнути, виконавши кілька простих вимог. Пожежа може виникнути в силу великої кількості різноманітних обставин, які неможливо передбачити, проте можна підготувати засоби для боротьби 3 нею.

Мета роботи - підвищення пожежної безпеки на етапі проєктування будівель. Запропонований програмний додаток покликаний допомогти відповідальним за пожежну безпеку особам перевірити основні параметри будівлі та їх відповідність нормам пожежної безпеки.

Аналіз існуючих рішень. Пожежна безпека на будь якому підприємстві $\epsilon$ невід’ємною частиною робочого процесу. В Україні ця сфера регламентується Правилами пожежної безпеки в Україні, які затверджуються наказом Міністерства внутрішніх справ України, зі змінами, які періодично вносяться

(C) Чернецький Я.С., Ліхоузова Т.А., 2021 


\section{«Системні технології» 5 (136) 2021 «System technologies»}

відповідними наказами [1, 2]. Виконання зафіксованих на законодавчому рівні вимог пожежної безпеки є обов'язковим для усіх суб'єктів, що ведуть свою господарські діяльність на території України, незалежно від форм власності, сфери роботи, кількості співробітників та інших аспектів.

Пожежна безпека - це сукупність практик, призначених для зменшення руйнувань, спричинених пожежею. До заходів протипожежної безпеки належать ті, які заплановані під час будівництва будівлі або впроваджені в конструкціях, що вже стоять, та робота з мешканцями та відвідувачами будівлі. Пожежна безпека об'єкта мусить забезпечуватися наступними системами:

- системою запобігання пожежі;

- системою протипожежного захисту;

- організаційно-технічними заходами.

Зважаючи на те, що пожежна безпека $\epsilon$ дуже важливою частиною функціонування будь-якого об’єкта інфраструктури, було розроблено багато різноманітних додатків, які допомагають людям проектувати, перевіряти будівлі щодо пожежної безпеки, а також симулювати надзвичайні ситуації. Таким чином усі подібні програми можна розділити на декілька груп за функціональним призначенням:

- симуляція пожежі;

- програми для створення плану будівлі;

- для архітекторів.

В результаті аналізу [3-6] було отримано порівняльну таблицю існуючих програм даної сфери (табл. 1).

Головним недоліком усіх програм є їхня ціна, яка в силу невисокої конкуренції на ринку є досить великою для пересічної людини. Повністю безкоштовним є лише FDS, проте це тільки ядро для обчислень, яке не може самостійно функціонувати, а потребуватиме взаємодії з платними модулями. 
Порівняння існуючих рішень

\begin{tabular}{|c|c|c|c|c|c|c|c|}
\hline \multirow[b]{2}{*}{ Функціональні можливості } & \multicolumn{7}{|c|}{ Програмні рішення } \\
\hline & 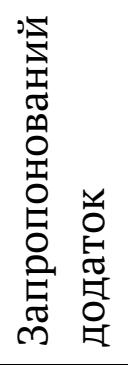 & 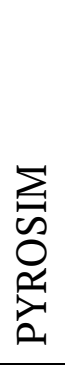 & 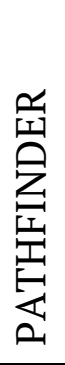 & 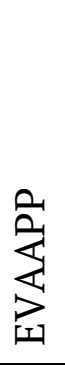 & $\begin{array}{l}\text { 离 } \\
\text { 童 }\end{array}$ & 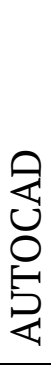 & 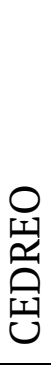 \\
\hline Побудова плану будівлі & + & + & + & + & + & + & + \\
\hline Можливість симуляції пожежі & - & + & + & - & - & - & - \\
\hline Розрахунок часу евакуації & - & - & + & + & - & - & - \\
\hline Експорт та імпорт в DXF & + & + & + & - & - & + & + \\
\hline Аналіз відповідності пожежним нормам & + & - & - & - & - & - & - \\
\hline Генерація звіту & + & + & + & + & + & - & - \\
\hline Безкоштовна версія & + & - & - & - & - & - & - \\
\hline Українська локалізація & + & - & - & + & - & + & - \\
\hline
\end{tabular}

Запропоноване рішення. Виходячи 3 вимог, що висувались до розроблюваної системи, було прийнято рішення про розробку кросплатформенного додатку, що зніме обмеження на вибір цільової платформи i збільшить кількість потенційних користувачів.

Розроблений додаток отримує вхідні дані від користувача, аналізує дані та генерує ix візуальне представлення. Після проведення аналізу даних створюється звіт з результатами перевірки. Оскільки додаток може використовуватись як незалежно, так і в якості підсистеми, було вирішено вибрати формати даних, які використовується в інших додатках даної сфери [7], що дозволить в майбутньому експортувати та імпортувати дані між додатками. Це формати DWG, DXF та TXT, із використанням структури запису даних подібної до тої, яка використовується в DXF. Для формування звіту обрано файловий формат PDF. 
«Системні технології» 5 (136) 2021 «System technologies»

Для реалізації очікуваного функціоналу було проаналізовано кілька технологій, обгрунтовано використання технології Drag\&Drop та методу створення PDF-файлів з використанням C++ та Qt [8].

Дані з нормативних актів, які будуть використовуватися як еталон для перевірки відповідності плану будівлі пожежним нормам, зберігаються у нереляційній базі даних. Це пов'язано з тим, що вони не мають чіткої структури і використання реляційної бази буде складним та недоцільним у цьому випадку. Для зберігання даних про будинки обрано реляційну базу даних, адже такі дані буде зручно подати у вигляді взаємопов'язаних таблиць. При виборі СУБД вибір зупинився на MongoDB та MySQL, як одних з лідерів ринку.

Багатошарова архітектура ідеально підходить для програм Qt [9]. Ця архітектура забезпечує чіткий розподіл відповідальності та сприяє гарному дизайну компонентів. Програму умовно можна розділити на декілька модулів, кожен з яких відповідатиме за виконання певного функціоналу і обміну даними між модулями.

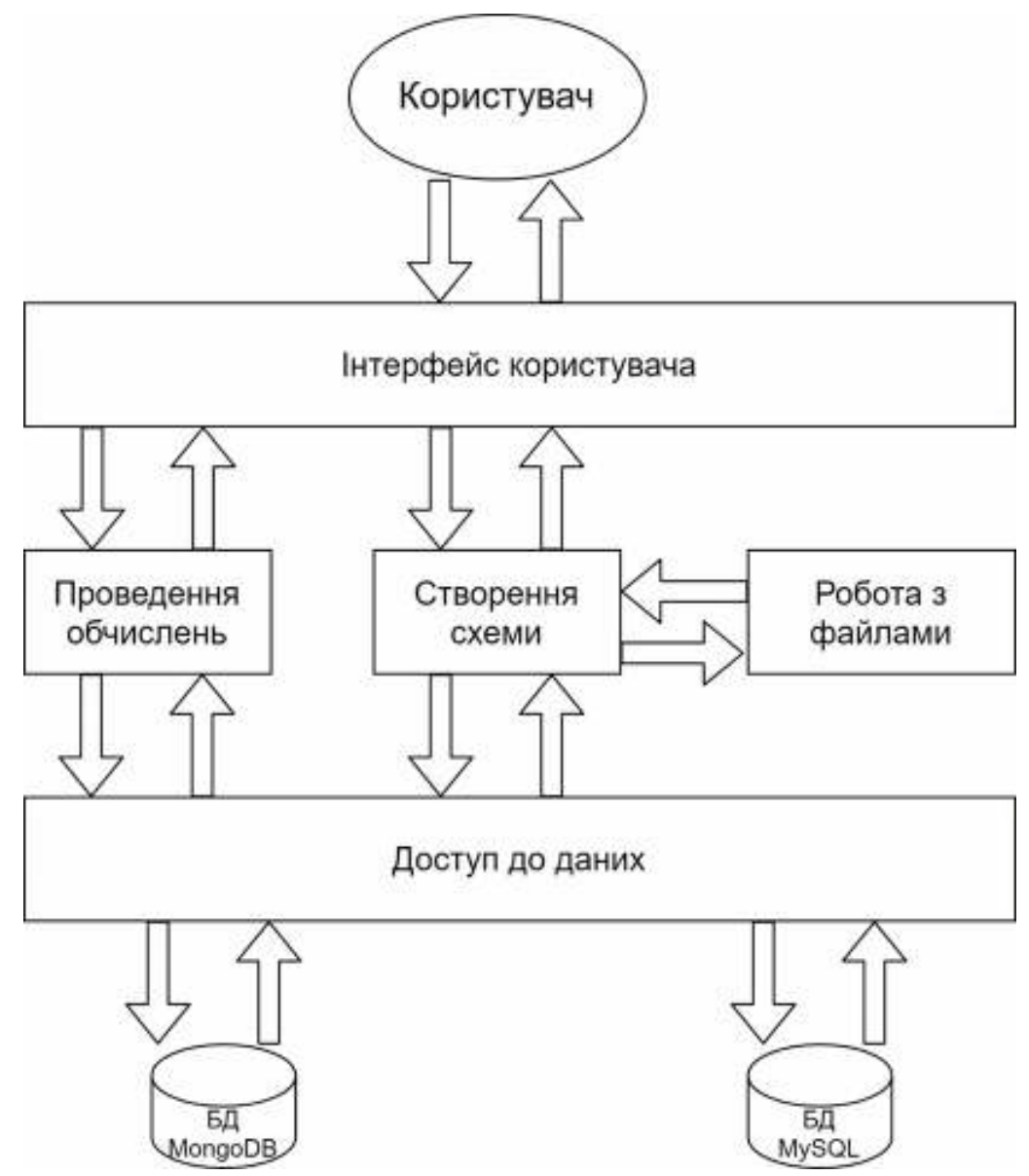

Рисунок 1 - Взаємодія програмних модулів підсистеми

Так даний програмний продукт містить наступні незалежні модулі: 
«Системні технологіï» 5 (136) 2021 «System technologies»

- модуль роботи з базою даних MongoDB;

- модуль роботи з базою даних MySQL;

- модуль для роботи з файлами;

- модуль для створення плану будівлі;

- модуль обчислень;

- модуль графічного інтерфейсу.

Їхню взаємодію показано схематично на рис. 1.

Інтерфейсом розробленої програми являється програмне вікно цільової операційної системи. Дана програма складається з двох вікон, одне з яких головне, а друге відкривається натисканням на головному вікні кнопки «Створити схему». На допоміжному вікні присутні канва для малювання схеми і панель 3 доступними елементами, які можна переміщувати на схему. Також наявні поля для вводу розмірів і ручного позиціонування елементів плану будівлі.

На головному вікні програми містяться кнопки управління, текстове поле для відображення результатів аналізу, та поле для відображення план-схеми, що аналізується.

Користувачу доступний наступний перелік кнопок:

- завантажити з файлу;

- зберегти в файл;

- аналізувати;

- генерувати звіт;

- створити схему.

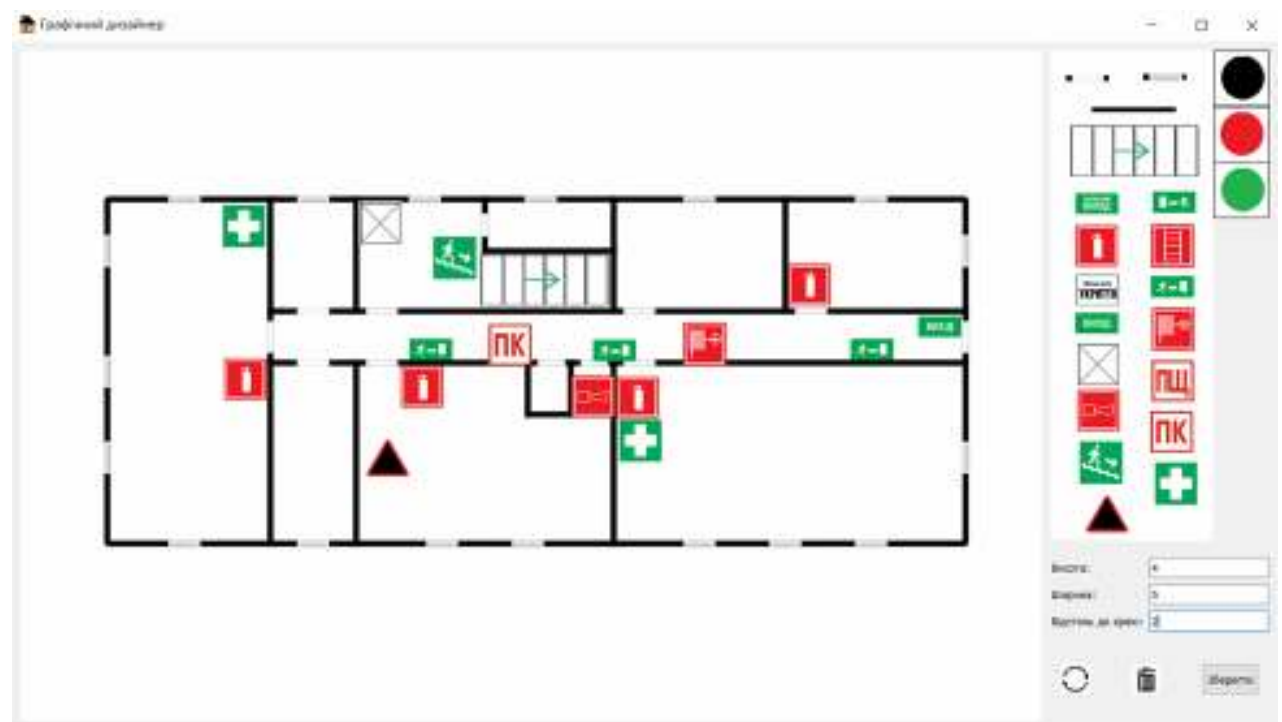

Рисунок 2 - Вікно графічного дизайнера програми 
«Системні технологіï» 5 (136) 2021 «System technologies»

Завантаживши в програму файл-схему, або створивши схему будинку 3 використанням графічного дизайнера програми можна здійснити аналіз обраної схеми. В результаті можна отримати повідомлення про відповідність схеми нормам пожежної безпеки, або повідомлення про наявність порушень, та їх список (рис. 3). За результатами роботи програми доступна можливість генерації звіту у форматі pdf.

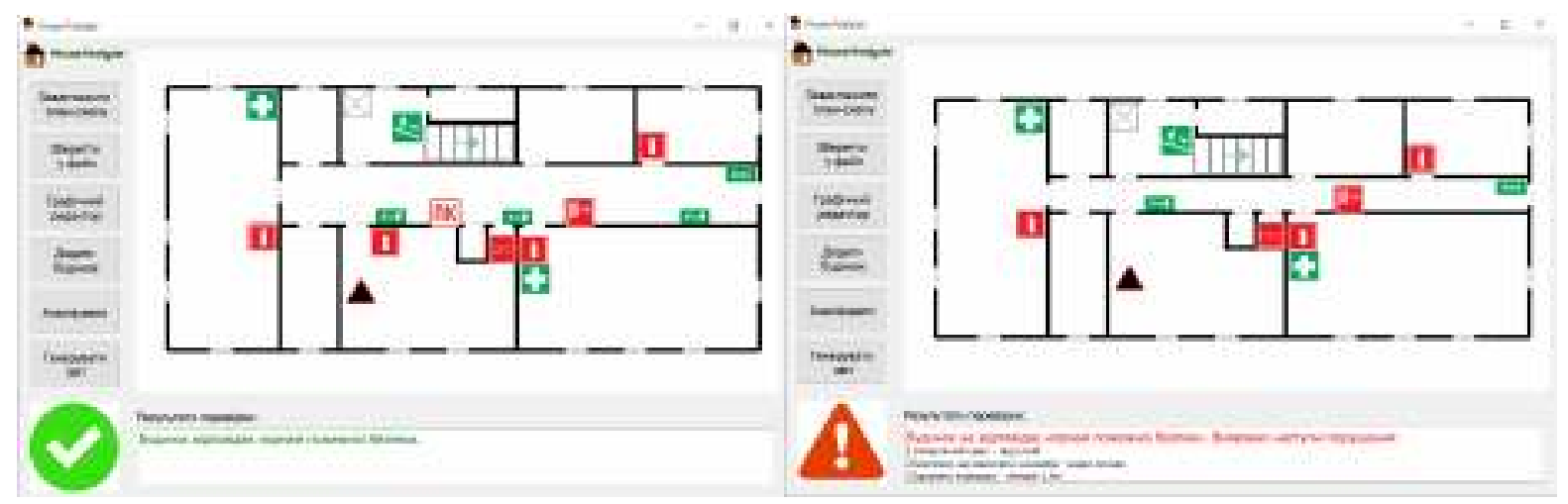

Рисунок 3 - Результати перевірки

Програма оформлена як установчий пакет з інсталяційним інтерфейсом, що дозволить вільно поширювати їі серед інших користувачів, а також у випадку необхідності передбачена можливість видалити програму через стандартну панель керування операційної системи або за допомогою інсталяційного файлу.

Розроблена підсистема розрахована на широке коло користувачів завдяки своїй простоті та зручному інтерфейсу. Правильний розподіл на класи дозволить у майбутньому вдосконалювати програму.

Висновки. Запропонований програмний додаток має перспективи для використання серед різноманітних груп населення, починаючи від власників приватних будинків, які хочуть перевірити його безпеку на випадок надзвичайної ситуації, і закінчуючи архітекторами та працівниками ДСНС, які проводитимуть моніторинг стану житлових та нежитлових об'єктів 3 можливістю зручного контролю та веденням статистики.

\section{ЛІТЕРАТУРА / ЛИТЕРАТУРА}

1. Пожежна небезпека в будівлях: огляд, оцінка та стратегії покращення пожежної безпеки [Електронний ресурс] - 2020.

https://www.emerald.com/insight/content/doi/10.1108/PRR-12-2018-0033/full/html 


\section{«Системні технології» 5 (136) 2021 «System technologies»}

2. Пожежна безпека на підприємстві: правила та організація [Електронний ресурс] - 2018. https://profiteh.ua/pozhezhna-bezpeka-na-pidpryiemstvi-pravyla-taorhanizatsiia/

3. Fire safety 1: Understanding fire, fire precautions and prevention [Електронний pecypc] - 2017. https://www.pcs.org.uk/your-union/activists-resources/organisingyour-workplace/health-and-safety/hazards-and-health-a-to-z

4. Fire Dynamics and Smoke Control [Електронний ресурс] - 2021.

https://www.thunderheadeng.com/pyrosim/?gclid=CjwKCAjw-

e2EBhAhEiwAJI5jg5d6yeXxPsNc6D6kz1yF7T6ng3wB46VTByFcXujWR0mrhpjF0nbrix oCyOMQAvD_BwE

5. Eva-App - розрахунок часу евакуації [Електронний ресурс] - 2021. https://evaapp.biz/static/lending\#components

6. AutoCAD Software [Електронний ресурс] - 2021.

https://www.autodesk.com/products/autocad/overview?term=1-YEAR

7. DXF Reference - Autodesk Help [Електронний ресурс] - 2012.

http://help.autodesk.com/cloudhelp/2018/ENU/AutoCAD-DXF/files/index.htm

8. Creating PDF/A documents with Qt [Електронний ресурс] - 2017.

https://www.kdab.com/creating-pdfa-documents-qt/

9. What is a multi layered software architecture? [Електронний ресурс] - 2018.

https://hub.packtpub.com/what-is-multi-layered-software-architecture/

\section{REFERENCES}

1. Fire hazard in buildings: review, assessment and strategies to improve fire safety [Electronic resource] - 2020.

https://www.emerald.com/insight/content/doi/10.1108/PRR-12-2018-0033/full/html 2. Fire safety at the enterprise: rules and organization [Electronic resource] - 2018. https://profiteh.ua/pozhezhna-bezpeka-na-pidpryiemstvi-pravyla-ta-orhanizatsiia/ 3. Fire safety 1: Understanding fire, fire precautions and prevention [Electronic resource] - 2017. https://www.pcs.org.uk/your-union/activistsresources/organising-your-workplace/health-and-safety/hazards-and-health-a-to-z 4. Fire Dynamics and Smoke Control [Electronic resource] - 2021. https://www.thunderheadeng.com/pyrosim/?gclid=CjwKCAjw-

e2EBhAhEiwAJI5jg5d6yeXxPsNc6D6kz1yF7T6ng3wB46VTByFcXujWR0mrhpjF0nbrix oCyOMQAvD_BwE

5. Eva-App - calculation of evacuation time [Electronic resource] - 2021. https://eva-app.biz/static/lending\#components

6. AutoCAD Software [Electronic resource] - 2021. 


\section{«Системні технологіï» 5 (136) 2021 «System technologies»}

https://www.autodesk.com/products/autocad/overview?term=1-YEAR

7. DXF Reference - Autodesk Help [Electronic resource] - 2012.

http:/help.autodesk.com/cloudhelp/2018/ENU/AutoCAD-DXF/files/index.htm

8. Creating PDF/A documents with Qt [Electronic resource] - 2017.

https://www.kdab.com/creating-pdfa-documents-qt/

9. What is a multi layered software architecture? [Electronic resource] - 2018. https://hub.packtpub.com/what-is-multi-layered-software-architecture/

Received 11.05.2021. Accepted 14.05.2021.

\section{Проектирование и анализ плана строения согласно нормам пожарной безопасности}

Предложена система для автоматизации проверки сооружений на пожарную безопасность на основе проектной документации. Главным недостатком всех существующих программ является их цена, которая в силу невысокой конкуренции на рынке достаточно большая для обычного человека. Данная разработка является ореn-source программой, так что каждый желающий сможет воспользоваться ее функционалом. На загруженном или созданном непосредственно в программе плане дома программа обнаруживает и выделяет проблемные места и предоставляет объяснение пункта правил и причин его несоответствия. В результате работы программы пользователь может получить отчет по результатам анализа и $2 D$ модель дома, которую потом можно будет использовать в других программах. Программное приложение может использоваться как на этапе проектирования здания, так и на этапе принятия в эксплуатацию.

\section{Design and analysis of the building plan according to fire safety standards}

Hundreds of fires occur in residential and non-residential premises in Ukraine every day. Each of them to one degree or another damages the building itself, causes material damage, and poses a threat to human life. The consequences of a fire are often exacerbated by noncompliance with fire safety regulations, which could be avoided by following a few simple requirements. A fire can occur due to a large number of different circumstances that are impossible to predict, but you can prepare means to combat it.

The purpose of the work is to increase fire safety at the design stage of buildings. The proposed software application is designed to help those responsible for fire safety to check the basic parameters of the building and their compliance with fire safety standards on the basis of project documentation.

Because fire safety is a very important part of any infrastructure, many different applications have been developed to help people design, inspect buildings for fire safety, and simulate emergencies. all such programs can be divided into several groups by functional purpose: fire simulation; programs for creating a building plan; programs for architects. The main disadvantage of all existing programs is their price, which due to low competition in the market is quite high for the average person. Only FDS is completely free, but it is only a computing core that cannot function on its own, but will need to interact with paid modules. 


\section{«Системні технології» 5 (136) 2021 «System technologies»}

The proposed development is an open-source program, so everyone will be able to use its functionality. On the plan of the house loaded or created directly in the program, the program identifies and identifies problem areas and provides explanations on the point of the rules and the reasons for its inconsistency. As a result of the program, the user can receive a report on the results of the analysis and a 2D model of the house, which can then be used in other programs.

The software application can be used both at the design stage of the building and at the commissioning stage.

Ліхоузова Тетяна Анатоліївна - к.т.н., доцент кафедри технічної кібернетики, Національний технічний університет України «Київський політехнічний інститут імені Ігоря Сікорського».

Чернецький Ярослав Сергійович - студент кафедри технічної кібернетики, Національний технічний університет України «Київський політехнічний інститут імені Ігоря Сікорського».

Лихоузова Татьяна Анатольевна - к.т.н., доцент кафедры технической кибернетики, Национальный технический университет Украины «Киевский политехнический институт имени Игоря Сикорского».

Чернецкий Ярослав Сергеевич - студент кафедры технической кибернетики, Национальный технический университет Украины «Киевский политехнический институт имени Игоря Сикорского».

Likhouzova Tetiana - PhD, associate professor, Department of Technical Cybernetics National Technical University of Ukraine «Igor Sikorsky Kyiv Polytechnic Institute».

Chernetskyi Yaroslav - student of the Department of Technical Cybernetics National Technical University of Ukraine «Igor Sikorsky Kyiv Polytechnic Institute». 